\title{
Genus Cryptopimpla Taschenberg new to Sulawesi, Indonesia, with description of a new species (Hymenoptera, Ichneumonidae, Banchinae)
}

\author{
Keizo Takasuka ${ }^{1, \dagger}$, Kyohei Watanabe ${ }^{2, \ddagger}$, Kazuhiko Konishi ${ }^{3, \$}$ \\ 062-8555, Japan \\ † urn:lsid:zoobank.org:author:7D8079A8-B52C-4C6F-9F52-92D992B09C7B \\ † urn:lsid:zoobank.org:author:B66171F7-93BC-44CF-8DFF-EFE241955323 \\ § urn:lsid:zoobank.org:author:912B5FF3-18CE-412F-B100-E7E60410FA37 \\ Corresponding author: Keizo Takasuka (keizaf@gmail.com)
}

I Entomological Laboratory, Faculty of Agriculture, Ehime University, Tarumi 3-5-7, Matsuyama, Ehime 790-8566, Japan 2 Graduate School of Agricultural Science, Kobe University, Rokkodaicho 1-1, Nada, Kobe, Hyogo 657-8501, Japan 3 National Agricultural Research Center for Hokkaido Region, Sapporo, Hokkaido

Academic editor: Gavin Broad | Received 25 May 2011 | Accepted 8 July 2011 | Published 21 October 2011

urn:lsid:zoobank.org:pub:9C72879D-212F-4D63-BC06-6AAB363E079E

Citation: Takasuka K, Watanabe K, Konishi K (2011) Genus Cryptopimpla Taschenberg new to Sulawesi, Indonesia, with description of a new species (Hymenoptera, Ichneumonidae, Banchinae). Journal of Hymenoptera Research 23: 65-75. doi: $10.3897 /$ JHR.23.1595

\begin{abstract}
Cryptopimpla sulawesiensis sp. n. (Ichneumonidae: Banchinae: Atrophini) is described from the island of Sulawesi, Indonesia (Sundaland). This is the first known representative of the genus in Indonesia and is also the southernmost record of Cryptopimpla in the Oriental region. The presence of Cryptopimpla in Sulawesi, which belongs to Wallacea, indicates the potential distribution of Cryptopimpla in the Indochina Peninsula, Sundaland (other than Sulawesi Is.) and possibly Australia, where there have been no records of the genus.
\end{abstract}

\section{Keywords}

Atrophini, Cryptopimpla sulawesiensis sp. n., Gorontalo, Oriental region, taxonomy 


\section{Introduction}

The genus Cryptopimpla Taschenberg is a relatively large taxon of the tribe Atrophini, subfamily Banchinae, family Ichneumonidae, containing 46 described species recorded worldwide except for the Australian, Oceanian (Notogaean realm) and Neotropical (Neogaean realm) regions, with greatest species richness in the temperate area (Yu et al. 2005; Sheng and Zheng 2005; Kuslitzky 2007). The genus seems to be poorly represented in tropical areas; e.g. there is only one species in the Ethiopian region (South Africa) (Morley 1916) and there are no known species in the Neotropical region. Although Chandra and Gupta (1977) and Sheng (2011) recognized 16 species of Cryptopimpla from tropical area of the Oriental region, only five of these were recorded from tropical areas, namely Myanmar and the Philippines, and the distributions of the remaining species were restricted to non-tropical areas such as north India, Ryukyu, Jiangxi Province and Taiwan. This may be due to inadequate collections in tropical areas. In fact, there have been no additional Cryptopimpla species recorded from tropical area of the Oriental region since Chandra and Gupta's (1977) monograph. Although Sundaland has no record of Cryptopimpla (Chandra and Gupta 1977), it is possible that they would potentially exist in mountainous regions as Chandra and Gupta (1977) stated that all the Oriental species of the genus recorded so far inhabit mountains. The ichneumonid fauna in 'tropical' mountainous regions more closely resembles that of temperate areas and species richness is also higher than in tropical lowlands (Gauld 1987).

In 2009 (January to March), one of us, KT, had an opportunity to investigate the ichneumonid fauna of the Tilongkabila mountains, Prov. Gorontalo, north Sulawesi, Indonesia. Amongst the specimens collected by the survey, a number of specimens of a Cryptopimpla species were found. It was concluded that the species is new to science; here we describe this species and record it as the first appearance of Cryptopimpla in the island of Sulawesi, Indonesia.

\section{Materials and methods}

The Tilongkabila mountains (mountain top; alt. $1510 \mathrm{~m} ; 0^{\circ} 35.18^{\prime} \mathrm{N}, 123^{\circ} 13.22^{\prime} \mathrm{E}$ ) lie in Bogani Nani Warta Bone National Park and are covered by tropical primeval forest from the foot. Four Malaise traps were deployed every $300-400 \mathrm{~m}$ altitude from $100 \mathrm{~m}$, at about 100, 500, 900 and $1200 \mathrm{~m}$, along the trail of the Tilongkabila mountains for about six weeks from the end of January 2009 to the beginning of March (rainy season). GPS data of the trapping points are indicated in the type specimen data. Malaise bottles were exchanged every two weeks. Net sweeping was also conducted along the trail and around the camp site as KT climbed.

Specimens used in this study were collected by both Malaise traps and sweep net. Observations of the specimens were made by stereomicroscope (OLYMPUS SZ60; LEICA M165-C), light microscope (OLYMPUS BX41) and video microscope (KEYENCE VHX-1000). Male terminalia were treated in $10 \% \mathrm{KOH}$ at about $20^{\circ} \mathrm{C}$ for 24 
hours, then washed in distilled water and observed in $70 \%$ ethanol. Digital images were edited using Adobe Photoshop ${ }^{\circledR}$ CS3.

Morphological terminology mainly follows Gauld (1991). We referred to Snodgrass (1941) and Eady (1968) for male genitalia and microsculpture descriptions, respectively. The following abbreviations were used: minimum length of ocello-ocular line $(\mathrm{OOL})$, minimum length of postocellar line (POL), maximum diameter of posterior lateral ocellus (OD), length of malar space (MSL), and character states of the holotype (HT). Ovipositor length is expressed as the length of the ovipositor sheaths (i.e. the length of the ovipositor beyond the hypopygium).

The specimens examined in this study are deposited in the National Institute for Agro-Environmental Sciences, Tsukuba city, Ibaragi (NIAES), the collection of Ehime University Museum (EUM) and the Natural History Museum, London (BMNH).

\section{Taxonomy}

\section{Genus Cryptopimpla Taschenberg, 1863}

http://species-id.net/wiki/Cryptopimpla

See Townes (1970) and Yu et al. (2005) for synonymy.

Diagnosis. Cryptopimpla can be distinguished from all other banchine genera by the following combination of characters: lower end of occipital carina joining hypostomal carina above base of mandible; apical 0.3-0.4 of flagellum tapered towards apex; epomia absent; lower half of mesopleuron weakly convex or flat; posterior transverse carina of propodeum complete, or sometimes partly weak; pleural carina present, sometimes weak; areolet present, its petiole short or absent; $2 \mathrm{~m}-\mathrm{cu}$ with two bullae or a single wide bulla; hind wing with distal abscissa of $\mathrm{Cu} 1$ much closer to $1 \mathrm{~A}$ than to $\mathrm{M}$; first metasomal tergite with glymma, its spiracle before the middle, its dorsal profile strongly convex before the spiracle; median dorsal carina on first metasomal tergite absent; ovipositor shorter than hind tibia, sometimes upcurved.

Remarks. Keys to species of Cryptopimpla have been published for the following regions: Oriental (Chandra and Gupta 1977), Russian Far East (Kuslitzky 2007), China (Sheng and Zheng 2005; Sheng 2011), Japan (Momoi 1970), Europe (Aubert 1978; Schwarz 2003 treating only species with black metasomal tergites) and the Nearctic (Townes and Townes 1978). All the described species with black metasomal tergites, except for the Afrotropical C. rubrithorax Morley, 1916, are included in these keys. Although the species collected from Sulawesi possesses a black metasoma, it could not be assigned to any described species by the keys or by comparison with the description of $C$. rubrithorax, and most described species are very unlikely to be found in Sulawesi. None of the described species would be expected to match this species from Sulawesi, considering differences in climate and geography, because most described species are distributed in the temperate or subtropical regions, especially in the northern hemisphere. 


\section{Cryptopimpla sulawesiensis Watanabe, Konishi \& Takasuka, sp. n.} urn:Isid:zoobank.org:act:C438DCD7-CB8A-4A97-BE67-B636E29F7E9F http://species-id.net/wiki/Cryptopimpla_sulawesiensis

Figs $1-12$

Diagnosis. Cryptopimpla sulawesiensis can be distinguished from all other known species by the following combination of characters: frons without horn or tubercle; malar space 0.9-1.0 times as long as basal width of mandible; antenna uniformly cylindrical, not moniliform, apical part slender; antenna with 40-44 flagellomeres; palpi whitish yellow; posterior transverse carina and pleural carina on propodeum weak, not distinctly defined; apical part of tarsal claws bent at right angle; hind femur short and robust; areolet pentagonal, receiving $2 \mathrm{~m}$-cu medially; metasomal tergite I 1.7-2.0 (female) or 2.0-2.2 (male) times as long as maximum width; base of metasomal tergite I marked yellow to brown; ovipositor sheath $0.5-0.6$ times as long as hind tibia; mesosoma and metasoma in female largely black, without reddish parts or apical yellow bands on metasomal tergites.

Female (Figs 1, 3, 5, 6). Body 8.5-9.5 (HT: 8.6) mm long, fore wing 6.2-7.0 (HT: 6.4) $\mathrm{mm}$ long. Head polished, punctate, 0.6 times as long as wide in dorsal view; clypeus 0.5 times as long as wide, strongly convex in lateral view, punctures sparser than on face; face 0.8-1.0 (HT: 1.0) times as long as wide, median part with longitudinal ridge (Fig. 3); punctures on frons partly tend towards striation; malar space 1.0 times as long as basal width of mandible; basal portion of mandible convex; vertex and gena minutely and finely punctate; OOL/OD 1.0-1.1 (HT: 1.0); POL/OD 0.9-1.0 (HT: 1.1); antenna with 40-44 (HT: 40) flagellomeres; flagellomere I 3.0-3.8 (HT: 3.0) times as long as apical depth and 1.4-1.6 (HT: 1.6) times as long as flagellomere II.

Mesosoma matt, densely punctate (Figs 5, 6), distance between punctures shorter than puncture diameter, mesosoma 2.3-2.4 (HT: 2.3) times as long as width between tegulae; scutellum slightly more sparsely punctate than mesoscutum; lower half of mesopleuron slightly convex; upper end of epicnemial carina reaching lower 1/4 of pronotum; mesopleural suture straight, foveolate (Fig. 5); episternal scrobe small, slightly larger than propodeal spiracle (Fig. 5); propodeum punctate-reticulate with median portion reticulate rugose on anterior half, rugose on posterior half; posterior transverse carina present, interrupted by rugosity, pleural carina weak and other carinae absent (Fig. 6); border between propodeum and metapleuron indicated by furrow (Fig. 5); area posteroexterna short, about $1 / 4$ total length of propodeum (Fig. 6); propodeal spiracle round (Fig. 5). Legs: hind femur 5.2-5.8 (HT: 5.7) times as long as deep; hind tibia 8.0 times as long as wide; hind tarsomere I 2.4-2.6 (HT: 2.6) times as long as hind tarsomere II and 2.0-2.1 (HT: 2.1) times as long as longer hind tibial spur, respectively; tarsal claws 1.2 times as long as arolium, pectinate, their apical part bent at right angle. Wings (Fig. 7): fore wing with $\mathrm{Cu}-\mathrm{a}$ distad $\mathrm{Rs}+\mathrm{M}$ by 0.5-0.8 (HT: 0.5) times length of $\mathrm{Cu}-\mathrm{a}$, with pentagonal areolet receiving $2 \mathrm{~m}-\mathrm{cu}$ medially; hind wing with distal abscissa of $\mathrm{Cu} 1$ much closer to $1 \mathrm{~A}$ than to $\mathrm{M}$, basal abscissa of Cu1 2.0 times as long as cu-a. 


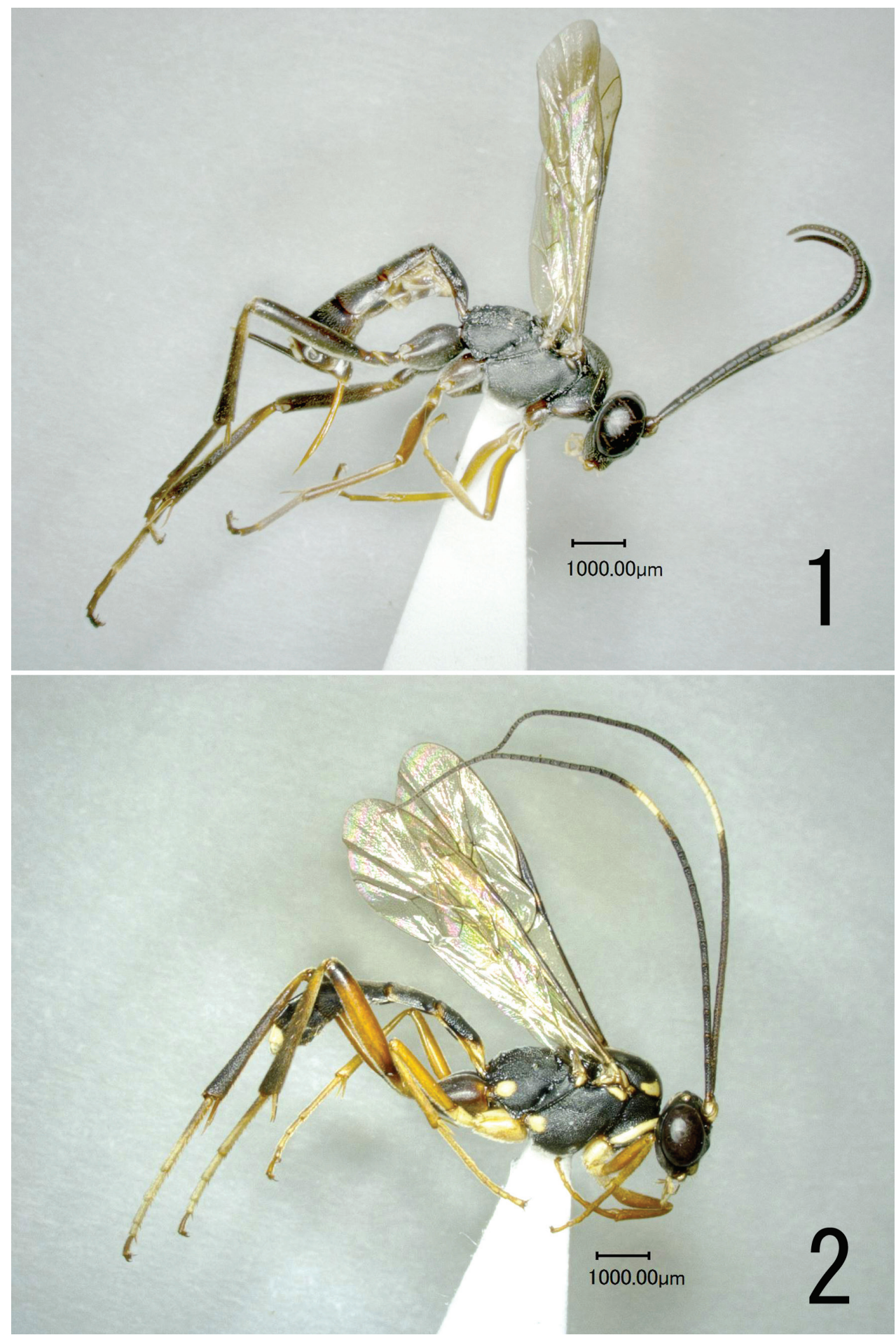

Figures I, 2. Lateral habitus of C. sulawesiensis sp. n. I Female (holotype) $\mathbf{2}$ male (paratype). 


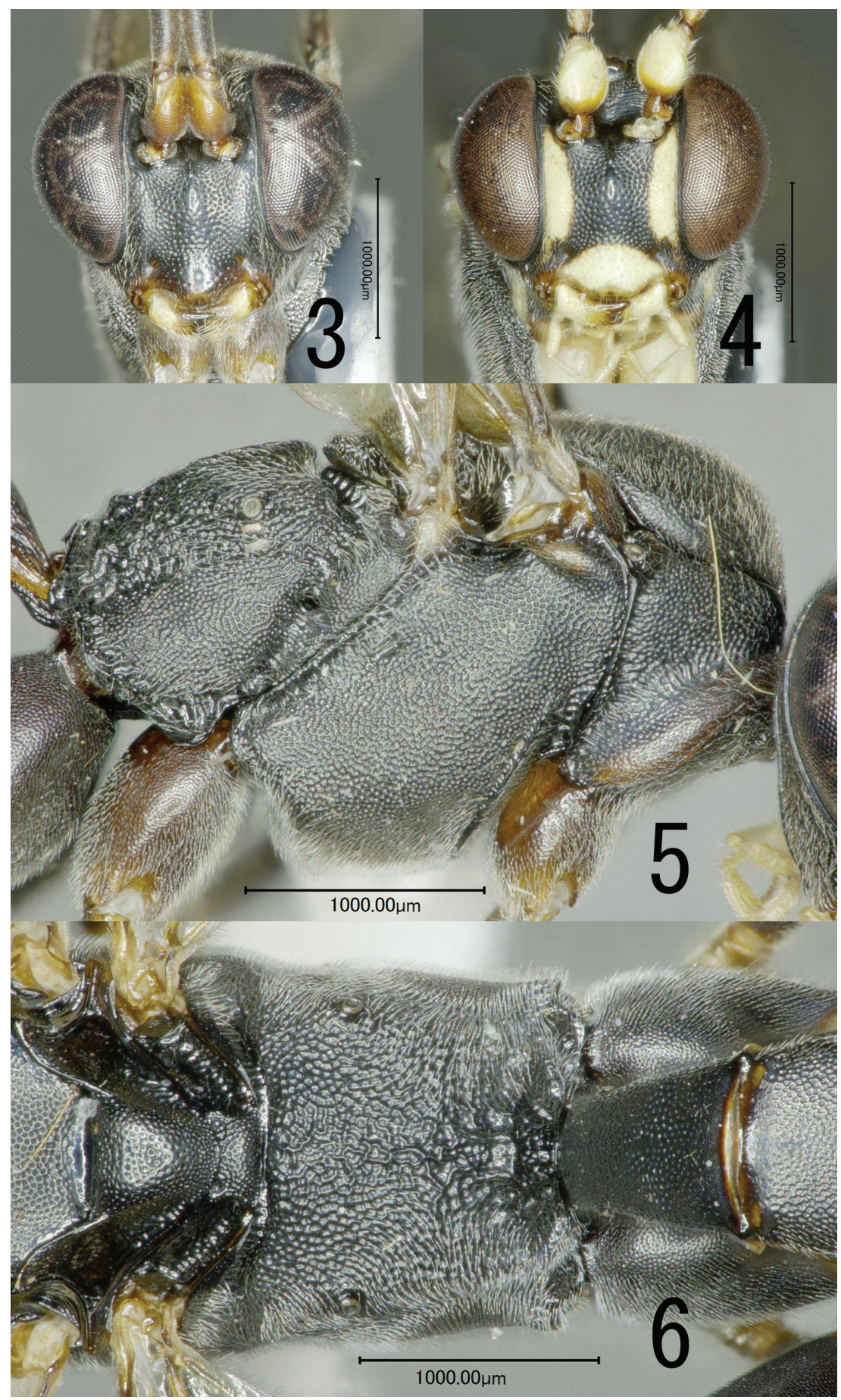

Figures 3-6. C. sulawesiensis sp. n. 3 Head, frontal view, female (holotype) 4 head, frontal view, male (paratype) $\mathbf{5}$ mesosoma, lateral view, female (holotype) $\mathbf{6}$ propodeum, dorsal view, female (holotype). Scale bar: $1.0 \mathrm{~mm}$. 


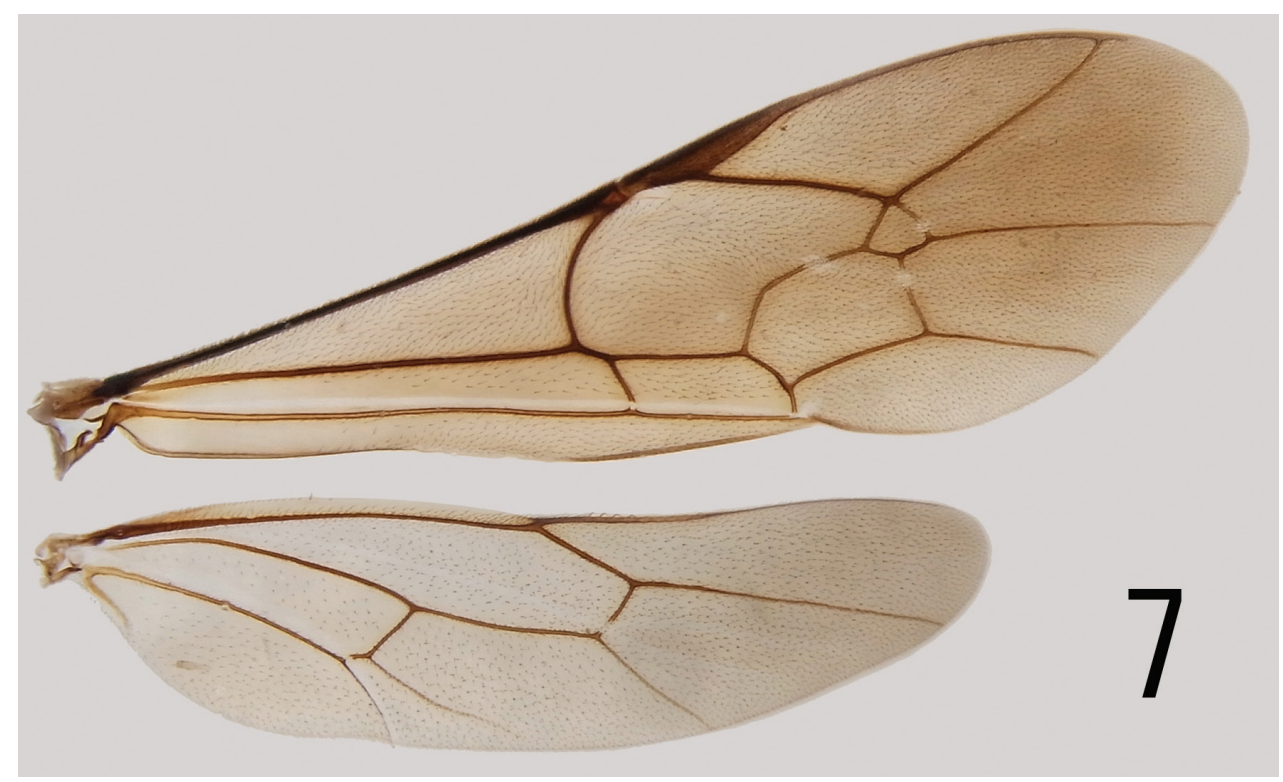

Figure 7. Fore and hind wings of C. sulawesiensis sp. n. (paratype).

Metasoma polished, punctate; tergite I 1.7-2.0 (HT: 1.7) times as long as maximum width, 1.3-1.5 (HT: 1.3) times as long as tergite II, densely punctate except for smooth basal part, narrow median longitudinal smooth line and posterior margin, punctures partly tend towards striation, each side of basal part weakly convex; tergites II and III punctate, punctures along anterior and posterior margins sparse and shallow, or partly absent; tergite IV and following tergites almost smooth; ovipositor 1.6-2.2 (HT: 1.6) mm, weakly up-curved, sheath 0.5-0.6 (HT: 0.6) times as long as hind tibia.

Coloration (Figs 1, 3, 5-7). Black; scape, pedicel, anterior part of clypeus, mandible base, fore and mid legs excluding black coxal base, apex of hind trochantellus, base of hind tibia, apices of hind tarsomeres I-IV, tibial spurs, tarsal claws excluding brown apex, base of metasomal tergite I and apical part of ovipositor sheath yellowish brown to brown; flagellomeres VIII-XVIII, posterior spot of tegula, basal sclerites of fore wing, posterior spot of metasomal tergite VI, and metasomal tergite VII white; palpi, and mandible excluding base and apex whitish yellow; ovipositor reddish brown; wings greyish hyaline.

Male (Figs 2, 4, 8-12). Similar to female, except following characters: body $7.2-$ $9.7 \mathrm{~mm}$ long, fore wing $6.0-7.7 \mathrm{~mm}$ long; face slightly wider, $0.7-0.8$ times as long as wide; malar space 0.9-1.0 times as long as basal width of mandible; OOL/OD 0.9-1.0; POL/OD 1.0-1.2; antenna with 44-46 flagellomeres; flagellomere I 4.3-5.0 times as long as apical width, 1.3 times as long as flagellomere II. Mesosoma 2.3-2.5 times as long as width between tegulae. Metasoma polished, punctate; tergite I 2.0-2.2 times as long as maximum width, 1.3-1.4 times as long as tergite II; hind tibia 8.0-8.4 times as long as wide; 7-9 distal hamuli. 


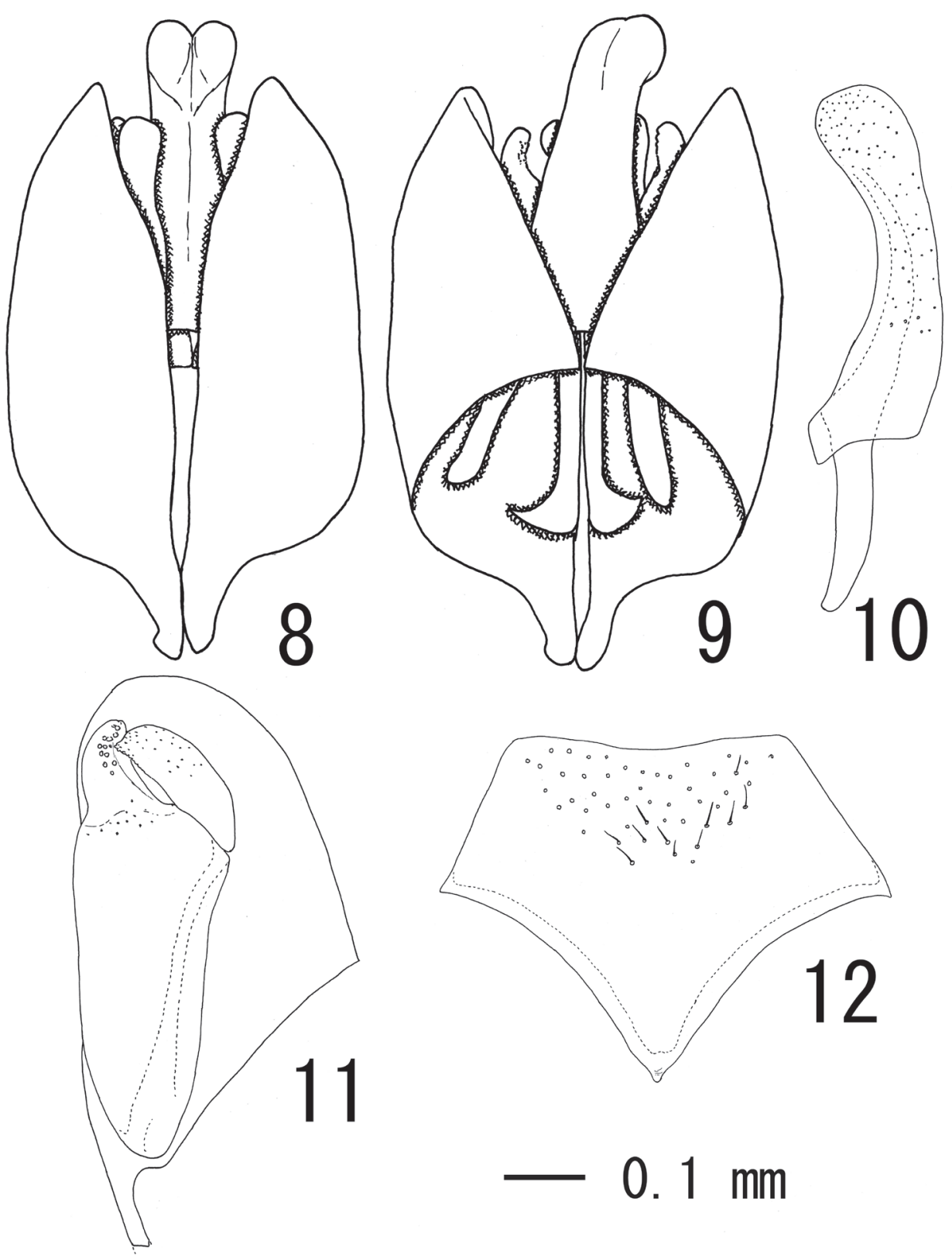

Figures 8-12. Male terminalia of C. sulawesiensis sp. n. (paratype). 8 Genital capsule ventral view 9 ditto, dosal view $\mathbf{I} \mathbf{0}$ aedeagus, lateral view $\mathbf{I} \mathbf{I}$ left paramere, inner aspect $\mathbf{I} \mathbf{2}$ subgenital plate, ventral view.

Male terminalia: subgenital plate pentagonal with median portion of apical margin weakly concave (Fig. 12); apex of paramere not projected beyond apex of aedeagus (Figs 8, 9), apical margin round (Fig. 11); aedeagus with basal apodeme about half as long as penis valve (Fig. 10). 
Coloration markedly differs from female by presence of several yellowish markings (Figs 1-4). Body black; spots on scape and pedicel, mandible excluding brownish apex, clypeus, longitudinal stripe along facial orbit, palpi, collar, pair of anterolateral spots on mesoscutum, V-shaped marking on scutellum, tegula, subalar prominense, spots on posterodorsal corner of mesopleuron and metapleuron, basal sclerites of fore and hind wing, fore and mid coxae, trochanters, trochantelli, apex of hind trochanter and hind tarsomeres I-IV excluding black dorsal surface of tarsomere I whitish yellow; fore and mid legs except whitish yellow parts, base of hind coxa, hind trochanter excluding apex, hind femur excluding blackish base and apex, basal part of hind tibia yellowish to brownish red; flagellomeres XII-XIX, basal $1 / 3$ and posterior margin of metasomal tergite I and posterior margin of metasomal tergite II white. Wings and tarsal claws similar to female. Brown areas on hind femur and tibia sometimes darker

Type series. Holotype: + , Mts. Tilongkabila, Bogani Nani Warta Bone National Park, Prov. Gorontalo, North Sulawesi, INDONESIA, $100 \mathrm{~m}$ alt., 20.Feb.-3.Mar.2009, Keizo Takasuka leg. (Malaise trap, $\left.0^{\circ} 33.10^{\prime} \mathrm{N}, 123^{\circ} 10.34^{\prime} \mathrm{E}\right)$ (EUM). Paratypes: same locality and collector as holotype, 20, 100-500m alt., 6-9.Feb.2009 (NIAES); $2 \hat{0}$, 500-800m alt., 6-9.Feb.2009 (BMNH); 19, 900m alt., 7-18.Feb.2009 (Malaise trap, $\left.0^{\circ} 34.32^{\prime} \mathrm{N}, 123^{\circ} 11.41^{\prime} \mathrm{E}\right)(\mathrm{BMNH}) ; 1$ ㅇ, $1200 \mathrm{~m}$ alt., 7-19.Feb.2009 (Malaise trap, $0^{\circ} 34.36^{\prime} \mathrm{N}, 123^{\circ} 11.58^{\prime} \mathrm{E}$ ) (NIAES); 1 ㅇ, 500m alt., 19.Feb.-2.Mar.2009 (Malaise trap, $\left.0^{\circ} 34.04^{\prime} \mathrm{N}, 123^{\circ} 11.15^{\prime} \mathrm{E}\right)(\mathrm{EUM})$; $2 \hat{O}^{\circ}, 100-500 \mathrm{~m}$ alt., 2.Mar.2009 (NIAES); $12 \overbrace{}^{\Uparrow} 1$ ㅇ, 500-800m alt., 2.Mar.2009 (EUM).

Distribution. Indonesia (Sulawesi).

Etymology. The specific name is derived from Sulawesi, the type locality.

Biological note. Host unknown. Female wasps were, as a whole, caught in Malaise traps except for one individual caught by sweep net, whilst male wasps were caught exclusively by sweep net. On 2nd March, many male wasps were flying around one (unidentified) shrub growing between 500 and $800 \mathrm{~m}$.

\section{Discussion}

Cryptopimpla sulawesiensis sp. $\mathrm{n}$. is the first representative of the genus known from Sulawesi and also from Indonesia (Sundaland), thus extending the southernmost distribution of the genus in the Oriental region. The presence of Cryptopimpla in Sulawesi, belonging to Wallacea, indicates a potential distribution of Cryptopimpla in the Indochina Peninsula, Sundaland (other than Sulawesi) and possibly Australia, where there has been no record of the genus. In fact, specimens of an undescribed species of the genus have been collected in southern Vietnam (deposited in Naturalis Museum Leiden, Gavin Broad, pers. comm.). Further finds are expected.

Chandra and Gupta (1977) monographed 13 species and Sheng (2011) newly added three species of Oriental Cryptopimpla from India, Myanmar (Burma), Jiangxi Province, Taiwan and the Philippines. Of these Oriental species, C. sulawesiensis sp. n. is most similar to C. miltotibialis Chandra and Gupta and C. cristula Chandra and 
Gupta from India (males of both species unknown) in having the antenna with 40-44 flagellomeres, dense punctures on the mesosoma, a large, pentagonal areolet with $2 \mathrm{~m}$ $\mathrm{cu}$ at the middle, and the blackish metasoma, but $C$. sulawesiensis sp. n. can be distinguished from $C$. miltotibialis and $C$. cristula by the following points (characters of the two latter species in parentheses): metasomal tergite I somewhat shorter, 1.7-2.0 times as long as maximum width (more than 2.3 times as long as maximum width); hind femur short and robust, 5.2-5.8 times as long as maximum width (more than 6.7 times as long as maximum width); ovipositor shorter, its sheath 0.5-0.6 times as long as hind tibia (more than 0.68 times as long as maximum width); palpi whitish yellow (yellowish brown or black); metasomal tergites with some small yellowish, sometimes brownish areas (entirely black).

Chandra and Gupta (1977) stated that all the Oriental species of Cryptopimpla recorded so far inhabit mountains and C. sulawesiensis sp. n. also seems to prefer a mountainous environment as all specimens were caught along a trail in the Tilongkabila mountains. Gauld (1987) suggested that close relatives of temperate ichneumonid exist in 'tropical' mountains, where Cryptopimpla, which is clearly biased towards temperate areas, was actually discovered. However, we deployed four Malaise traps at various altitudes $(100,500,900$ and $1200 \mathrm{~m})$ in this study and females of C. sulawesiensis sp. $\mathrm{n}$. were caught at all altitudes.

\section{Acknowledgements}

The authors would like to express their cordial thanks to Gavin Broad (the Natural History Museum, London) for his critical reading of the manuscript and to two anonymous reviewers. They also wish to express their appreciation to Masahiro Sakai (EUM), Hiroyuki Yoshitomi (EUM), Shuji Okajima (TUA: Laboratory of Entomology, Tokyo University of Agriculture), Hiroaki Kojima (TUA) and Toshiharu Mita (TUA) for continuous guidance and encouragement throughout our study. The first author would like to express his cordial thanks to Aziz Salam and Muhammad Mukhtar (Gorontalo State University) for their helpful support during the study in Gorontalo and to Agnes Rampisela (Hasanuddin University) for her helpful support in obtaining an appropriate visa. He is also grateful to the following people for helping him to conduct the sampling survey in Gorontalo: I. Wayan Kertayasa, Hasyim Lahinta, Vikran Iskandar Putra, I. Nyoman Sukardi, Hamzah Ahmad, Iwan Yunus, Askar Nasibu, Lukman Mustaki and Hamzah Abubakar (members of Mapala Tarantula in Gorontalo State University). This study was conducted under research permission from RISTEK (No. 0005/FRP/ SM/I/09), and partly supported by the Discretionary Fund of the Dean of Faculty of Agriculture, Ehime University. 


\section{References}

Aubert JF (1978) Les Ichneumonides ouest-palearctiques et leurs hotes 2. Banchinae et Suppl. aux Pimplinae. Laboratoire d'Evolution des Etres Organises, Paris \& EDIFAT-OPIDA, Echauffour, 1-318 pp.

Chandra G, Gupta VK (1977) Ichneumonologia Orientalis, VII. The Tribes Lissonontini \& Banchini. Oriental Insects Monograph 7: 1-290.

Eady RD (1968) Some illustrations of microsculpture in the Hymenoptera. Proceedings of the Royal Entomological Society of London 43: 66-72.

Gauld ID (1987) Some factors affecting the composition of tropical ichneumonid faunas. Biological Journal of the Linnean Society 30: 299-312. doi: 10.1111/j.1095-8312.1987. tb00304.x

Gauld ID (1991) The Ichneumonidae of Costa Rica 1. Memoirs of the American Entomological Institute 47: 1-589.

Kuslitzky WS (2007) Banchinae. In: Lelej AS (Ed) 'Key to the insects of Russia Far East. Vol. IV. Neuropteroidea, Mecoptera, Hymenoptera. Pt 5.' Vladivostok: Dalnauka. 1052 pp.: 433-472. (in Russian)

Momoi S (1970) Ichneumonidae (Hymenoptera) of the Ryukyu Archipelago. Pacific Insects 12: $327-399$.

Morley C (1916) On some South African Ichneumonidae in the collection of the South African Museum. Annals of the South African Museum 15: 353-400.

Schwarz M (2003) Schlupfwespen (Insecta, Hymenoptera, Ichneumonidae) in den Hochlagen der Hohen Tauern (Osterreich). Teil 2: Bemerkungen zu ausgewahlten Arten einschlieslich der Beschreibung neuer Arten. Linzer Biologische Beitraege 35: 1097-1118.

Sheng ML, Zheng H (2005) The genus Cryptopimpla from China (Hymenoptera, Ichneumonidae). Acta Zootaxonomica Sinica 30: 415-418. [in Chinese]

Sheng ML (2011) Five new species of the genus Cryptopimpla Taschenberg (Hymenoptera: Ichneumonidae) with a key to species known from China. ZooKeys 117: 29-49. doi: 10.3897/zookeys. 117.1302

Snodgrass RE (1941) The male genitalia of Hymenoptera. Smithsonian Miscellaneous Collections 99: 1-86, 33 pls.

Townes HK (1970) The genera of Ichneumonidae, part 3. Memoirs of the American Entomological Institute 13: 1-30.

Townes HK, Townes M (1978) Ichneumon-flies of America North of Mexico: 7. Subfamily Banchinae, Tribes Lissonotini and Banchini. Memoirs of the American Entomological Institute 26: 1-614.

Yu DS, van Achterberg K, Horstmann K (2005) World Ichneumonoidea 2004. Taxonomy, biology, morphology and distribution. [CD/DVD computer program]. Taxapad ${ }^{\circledR}$, Vancouver, Canada. 